07

\title{
Мощный полупроводниковый обостритель импульсов с субнаносекундным быстродействием
}

\author{
(С) И.В. Грехов, А.Г. Люблинский, Ш.А. Юсупова \\ Физико-технический институт им. А.Ф. Иофрфе РАН, \\ 194012 Санкт-Петербург, Россия \\ e-mail: grekhov@mail.ioffe.ru
}

(Поступило в Редакцию 13 июля 2016 г.)

\begin{abstract}
Сверхбыстрое - субнаносекундное переключение высоковольтного диодного обострителя импульсов из блокирующего в проводящее состояние производится путем приложения к нему импульса перенапряжения со скоростью нарастания $\sim 10^{12} \mathrm{~V} / \mathrm{s}$ в блокирующем направлении. Образующийся при этом ударноионизационный фронт производит заполнение электронно-дырочной плазмой базовой области диода, переводя его в проводящее состояние. При этом принципиально важно предотвратить возможность пробоя по поверхности диодной структуры при перенапряжении. В работе представлены первые результаты исследования принципиально новой конструкции диодного обострителя импульсов, позволяющей полностью исключить деградацию краевого контура при импульсном перенапряжении. Проведенные эксперименты подтвердили работоспособность этой конструкции и перспективность работ по выяснению ее предельных возможностей.
\end{abstract}

DOI: 10.21883/JTF.2017.05.44459.1993

Возможность сверхбыстрого - субнаносекундного переключения из блокирующего в проводящее состояние высоковольтной кремниевой диодной $p^{+} N_{0} n^{+}$-структуры была показана в [1,2], а затем подтверждена в [3]. После этого был проведен большой комплекс исследований, в результате которых диодный лавинный переключатель - обостритель высоковольтных импульсов стал широко используемым прибором мощной импульсной техники субнаносекундного диапазона.

Процесс субнаносекундного переключения в диодном обострителе импульсов, согласно [4], происходит следующим образом. К диодной структуре $p^{+} N_{0} n^{+}$-типа, полученной, например, путем диффузий бора и фосфора с противоположных сторон кремниевой пластины $N_{0}$-типа проводимости и имеющей напряжение статического пробоя в запорном направлении порядка $1-2 \mathrm{kV}$, прикладывается в запорном направлении импульс напряжения, нарастающий со скоростью порядка $10^{12} \mathrm{~V} / \mathrm{s}$. При такой скорости подъема напряженность поля $E$ в расширяющейся области объемного заряда (ОO3) $p^{+} N_{0}$-перехода быстро достигает критической величины $E_{b} \approx 2 \cdot 10^{5} \mathrm{~V} / \mathrm{cm}$, при которой в квазистатических условиях развивается лавинный пробой. Однако при столь быстром подъеме напряжения того количества свободных носителей, которое создается термогенерацией в OO3, оказывается недостаточным для инициирования объемного пробоя. Когда поле нарастает до величины $\sim 5 \cdot 10^{5} \mathrm{~V} / \mathrm{cm}$, при которой начинается термополевая ионизация глубоких ловушек в кремнии, то образующиеся при этом электроны оказываются в области сверхсильного поля и производят быструю ионизацию атомов кремния, образуя электронно-дырочную плазму с высокой концентрацией. Поле в плазме падает, но нарастает в прилегающей ООЗ и т.д. Образующийся таким образом ионизационный фронт быстро перемещается в ОО3 к $N_{0} n^{+}$-переходу, оставляя за собой область, заполненную электронно-дырочной плазмой с высокой концентрацией. Когда фронт достигает $N_{0} n^{+}$-перехода, вся ОО3 оказывается заполненной электронно-дырочной плазмой, и диод переходит в проводящее состояние. Поскольку скорость движения фронта может на несколько порядков превышать насышенную скорость движения электронов, переключение диода со статическим напряжением пробоя $1-2 \mathrm{kV}$ происходит за время, меньшее 100 ps. Это самый быстрый из известных высоковольтных полупроводниковых переключателей - обострителей импульса.

Для надежной работы такого прибора необходимо обеспечить защиту от пробоя $p^{+} N_{0}$-перехода по поверхности при импульсном напряжении, значительно превышающем напряжение объемного пробоя в статических условиях. В силовой полупроводниковой электронике обычно используется конструкция краевого контура $p^{+} N_{0}$-перехода, позволяющая получить напряжение пробоя на поверхности большее, чем в объеме, впервые описанная в работе [5]. В этой конструкции диода, показанной на рис. 1, краевой контур (1) кремниевой пластины выполнен в виде кольцевой фаски таким образом, что площадь поперечного сечения уменьшается в направлении от высоколегированной $p^{+}$-области к слаболегированной $N_{0}$-области. В такой конструкции ширина ОО3 на поверхности краевого контура $W_{1}$ значительно больше, чем в объеме $W_{2}$; это позволяет уменьшить напряженность электрического поля на поверхности и предотвратить поверхностный пробой. Однако значительное увеличение ширины ОО3 на поверхности по сравнению с объемом в диодной структуре возможно только тогда, когда ширина ООЗ в объеме $W_{2}$ 


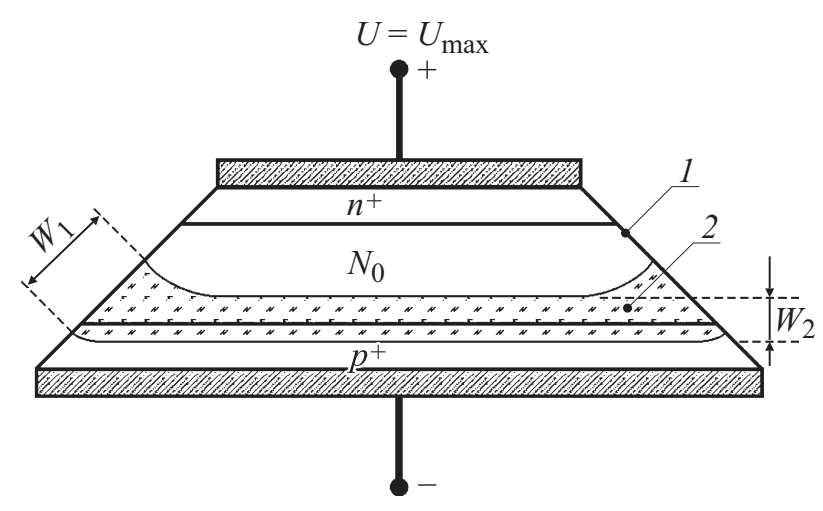

Рис. 1. Стандартная конструкция высоковольтного диода: 1 краевой контур, 2 - область объемного заряда (ОO3).

меньше, чем толщина $N_{0}$-базовой области. Это обычно и осуществляется при работе диодов в статических режимах, когда рабочее напряжение $U=U_{\max }$ меньше напряжения пробоя $p^{+} N_{0}$-перехода. Однако при работе в режиме обострителя импульсов, когда прикладываемое импульсное напряжение $U=U_{\max }$ в разы больше напряжения пробоя, ОО3 в объеме диода занимает всю $N_{0}$-базу и ширина ООЗ в объеме и на поверхности различается незначительно. Существенное увеличение толщины $N_{0}$-базы невозможно, поскольку оно приводит к уменьшению быстродействия и возрастанию остаточного напряжения во включенном состоянии. Кроме того, возможность быстрого формирования широкой ОО3 на поверхности ограничивается насыщением скорости движения носителей в сильных полях. Эти факторы приводят к тому, что вероятность пробоя по поверхности при перенапряжении резко возрастает и значительно снижается надежность работы лавинных обострителей.

Однако то обстоятельство, что при работе в режиме обострителя импульсов большое обратное напряжение прикладывается к диоду только на единицы наносекунд, дает возможность принципиально по-новому решать задачу защиты от пробоя по поверхности в диодной $p^{+} N_{0} n^{+}$-структуре, конструкция которой показана на рис. 2, $a[6]$. В этой структуре краевой контур блокирующего $p^{+} N_{0}$-перехода 1 замкнут накоротко металлизацией 2 с $p^{+}$-слоем 3 , а противоположный ему $n^{+}$-слой 4 имеет внешний диаметр $D_{1}$ значительно меньший, чем внешний диаметр $p^{+}$-слоя $D_{2}$. Таким образом, $n^{+}$-слой окружен кольцом исходного кремния с удельным сопротивлением, обычно лежащим в пределах 50-100 $\Omega \cdot \mathrm{cm}$.

Сопротивление $R$ кольца базовой области структуры в радиальном направлении равно $R=\frac{\rho}{2 \pi h} \ln \frac{D_{2}}{D_{1}}$, где $\rho$ - удельное сопротивление исходного кремния, $h-$ толщина базового слоя, $D_{1}$ и $D_{2}$ - диаметры верхнего и нижнего контактов соответственно.

Обостряемый импульс напряжения прикладывается к контактам $A B$ с отрицательной полярностью на $p^{+}$-слое. Протекающий при этом по кольцу исходного кремния ток создает на нем падение напряжения, которое сме- щает $p^{+} N_{0}$-переход в запорном направлении. Напряжение смещения изменяется от нуля на краевом контуре $p^{+} N_{0}$-перехода до максимума в его центре. Примерная форма распределения напряженности электрического поля на поверхности кольца показана на рис. 2, $b$, а в поперечном сечении $p^{+} N_{0}$-перехода - на рис. $2, c$. Когда при быстром подъеме напряжения поле в центре нарастает до величины $\sim 5 \cdot 10^{5} \mathrm{~V} / \mathrm{cm}$, то начинается термополевая ионизация ловушек и формируется ударно-ионизационный фронт, приводящий к сверхбыстрому переключению центральной части $p^{+} N_{0} n^{+}$-диода в проводящее состояние. Таким образом, формирование ударно-ионизационного фронта происходит в объеме материала, и возможность деградации диода вследствие поверхностного пробоя практически устраняется, поскольку ширина кольца значительно превышает толщину $N_{0}$-базовой области, и напряженность поля на поверхности кольца мала. При этом, конечно, обработка поверхности кольца и ее защита должны соответствовать обычным требованиям к защите поверхности краевого контура.

Опытные образцы диодов со структурой, приведенной на рис. 2, $a$, были изготовлены из $n$-кремния с удельным сопротивлением $\rho=100 \Omega \cdot \mathrm{cm}, p^{+} N_{0}$-переход с глубиной $65 \mu \mathrm{m}$ создавался диффузией бора

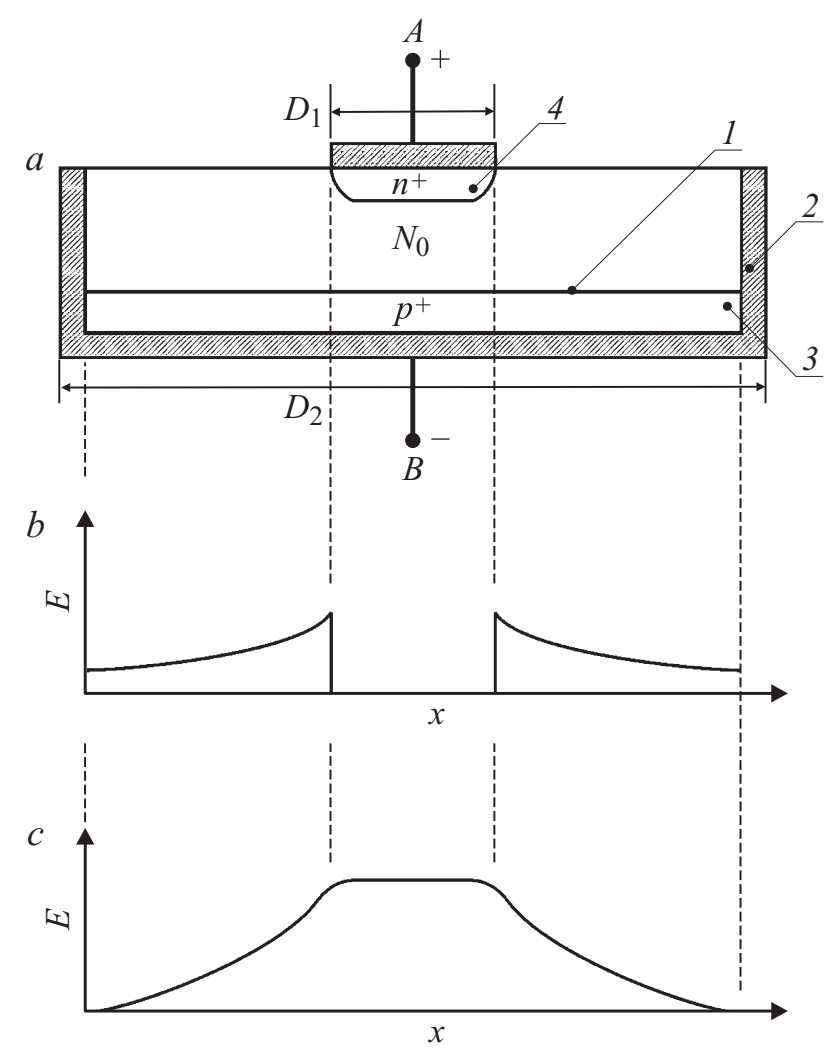

Рис. 2. $a-$ исследуемая конструкция диодной $p^{+} N_{0} n^{+}$-структуры: 1 - блокирующий $p^{+} N_{0}$-переход, 2 - замыкающая металлизация, $3-p^{+}$-слой, $4-n^{+}$-слой; $b-$ форма распределения напряженности поля по поверхности $N_{0}$ кольца; $c-$ форма распределения напряженности поля на $p^{+} N_{0}$-переходе. 


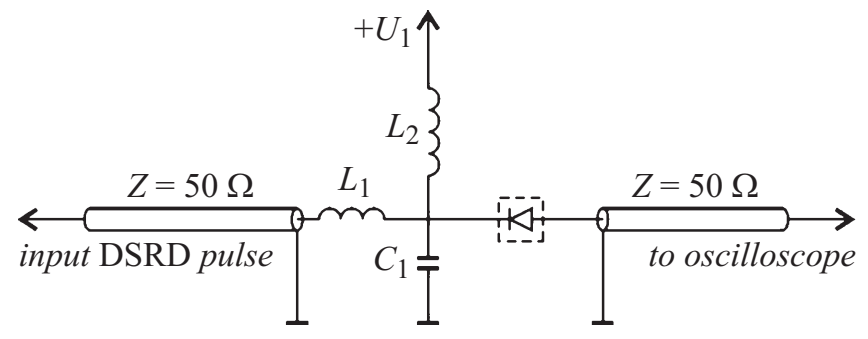

Рис. 3. Схема тестового модуля.

с поверхностной концентрацией $N_{s} \approx 1 \cdot 10^{20} \mathrm{~cm}^{-3}$, а $n^{+} N_{0}$-переход с глубиной $5 \mu \mathrm{m}$ создавался диффузией фосфора с $N_{s} \approx 1 \cdot 10^{21} \mathrm{~cm}^{-3}$. Внешний диаметр $n^{+}$-слоя $D_{1} \approx 1 \mathrm{~mm}, p^{+}$-слоя $D_{2} \approx 2 \mathrm{~mm}$, толщина центральной (,рабочей“) части $N_{0}$-слоя $\sim 100-110 \mu \mathrm{m}$, контакты к $n^{+}$- и $p^{+}$-слоям создавались путем химического никелирования и вжигания. Расчетное и измеренное в слаботочном режиме сопротивление кольца составляет около $1000 \Omega$.

Схема тестового модуля для исследования процесса переключения обострителей приведена на рис. 3. На вход модуля по коаксиальному кабелю с волновым сопротивлением $50 \Omega$ подается высоковольтный импульс наносекундной длительности, формируемый генератором на основе дрейфовых диодов с резким восстановлением (ДДРВ). В наших экспериментах амплитуда входного импульса регулировалась в диапазоне от 1 до $2 \mathrm{kV}$, фронт импульса составлял $\sim 0.6 \mathrm{~ns}$, а ширина импульса на полувысоте - $1.5 \mathrm{~ns}$. Обостряющий конденсатор $C_{1}$ заряжается входным высоковольтным импульсом через индуктивность $L_{1}$, при этом максимальное напряжение заряда конденсатора $C_{1}$ может быть выше, чем амплитуда входного импульса. Амплитуда и скорость нарастания входного импульса, а также параметры $C_{1}$ и $L_{1}$ подбираются таким образом, чтобы пробой обострителя происходил в момент, когда напряжение входного импульса близко к максимальному. Конденсатор $C_{1}$ обеспечивает постоянный уровень напряжения на обострителе в течение процесса пробоя, пока плазменный фронт перемещается по базовой области, а последующий разряд через обостритель и нагрузку $50 \Omega$ обеспечивает формирование субнаносекундного импульса тока при переключении обострителя в проводящее состояние. Постоянное напряжение от источника $U_{1}$ подается на обостритель через индуктивность $L_{2}$ и смещает $p^{+}-N_{0}$-переход обострителя в обратном направлении для уменьшения его емкости, что позволяет повысить скорость нарастания напряжения на обострителе и уменьшает долю входного наносекундного импульса, проходящую в нагрузку через емкость перехода до момента пробоя.

На рис. 4 показаны осциллограммы напряжения обостряемого импульса от ДДРВ-генератора на входе тестового модуля и выходного импульса после обострения. Участок медленного нарастания выходного импульса -
„Пьедестал“ - формируется емкостным током через обратно смещенную структуру диода и омическим током через кольцо $N_{0}$-слоя, а быстрый участок длительностью $\sim 100$ ps формируется ударно-ионизационным фронтом, заполняющим электронно-дырочной плазмой с высокой концентрацией центральную часть $N_{0}$-базового слоя структуры, показанной на рис. 2, $a$.

Хорошо видно, что с ростом напряжения обостряемого импульса растет напряжение выходного импульса и существенно увеличивается скорость его нарастания. Предварительные эксперименты показали также, что диоды надежно работают в частотном режиме.

Таким образом, в настоящей работе представлены первые результаты исследования принципиально новой конструкции диодного субнаносекундного обострителя мощных импульсов, позволяющей полностью исключить деградацию краевого контура $p^{+} N_{0}$-перехода при сверхвысоких импульсных перенапряжениях. Эти эксперименты подтвердили работоспособность предложенной конструкции и перспективность работ по выяснению ее предельных возможностей с целью повышения основных характеристик субнаносекундных диодных обострителей мощных импульсов.
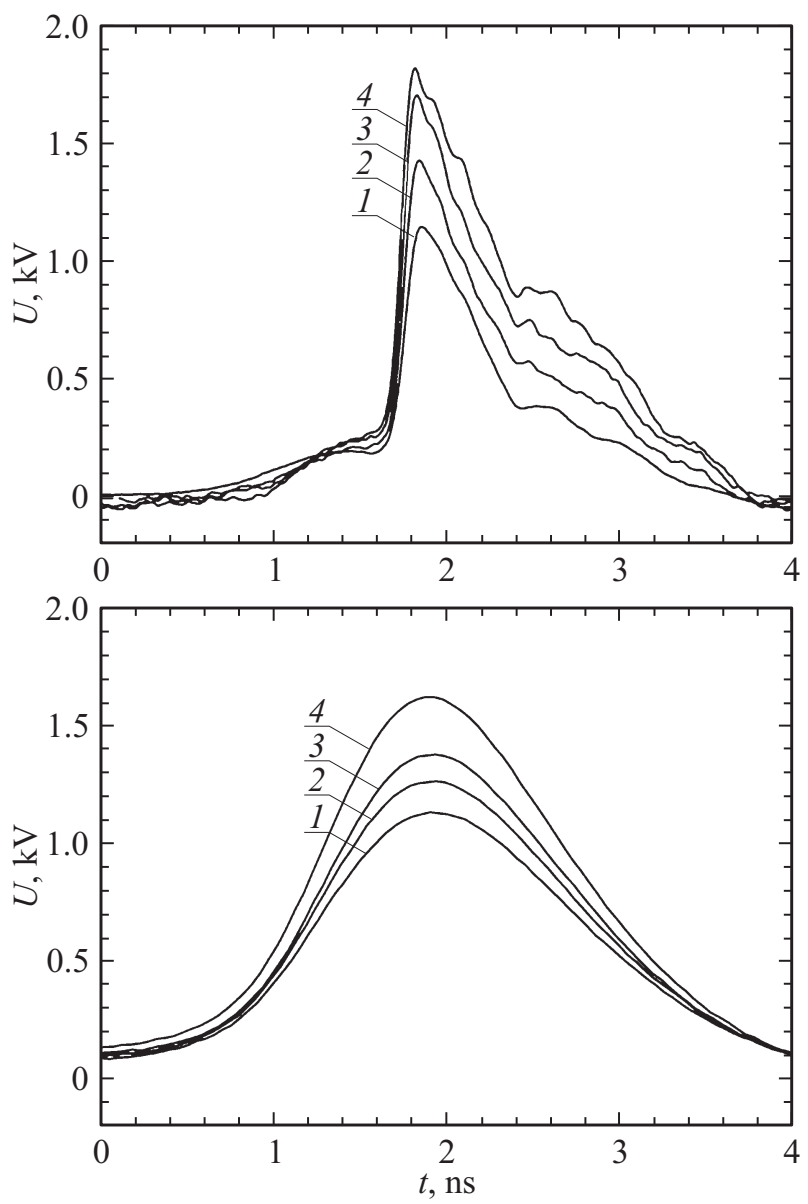

Рис. 4. Осциллограммы выходного импульса для нескольких значений пикового напряжения обостряемого импульса $U_{0}$ : $1-1.15 \mathrm{kV}, 2-1.25 \mathrm{kV}, 3-1.38 \mathrm{kV}, 4-1.62 \mathrm{kV}$. 
Работа выполнена за счет поддержки гранта Российского Научного фонда (проект № 14-29-00094).

\section{Список литературы}

[1] Грехов И.В., Кардо-Сысоев А.Ф. Письма в ЖТФ. 1979. Т. 5. Вып. 15. С. 950-953.

[2] Grekhov I.V., Kardo-Sysoev A.F., Kostina L.S., Shenderey S.V. // Electron. Lett., 1981. Vol. 17. N 12. P. 422-423.

[3] Benzel D., Pocha M. // Rev. Sci. Instrum. 1985 Vol. 56. N 7. P. $1456-1458$.

[4] Rodin P., Rodina A., Grekhov I. // J. Appl. Phys. 2005. Vol. 98. N 9. P. 094506(1-11).

[5] Davies R.L., Gentry F.E. // IEEE Tr. Electron Dev. 1964. Vol. 11. N 7. P. $313-323$

[6] Пат. РФ № 2016101357/08 (001875). Полупроводниковый диодный субнаносекундный обостритель импульсов / И.В. Грехов, А.Г. Люблинский. 2016. БИ № 19. 